\title{
Evaluating the tolerability and acceptability of an alcohol-based hand rub - real-life experience with the WHO protocol
}

\author{
Aline Wolfensberger*, Nina Durisch, Juliane Mertin, Evelyne Ajdler-Schaeffler and Hugo Sax
}

\begin{abstract}
Background: Optimizing user satisfaction with alcohol-based hand rubs (ABHR) may be vital to enhance hand hygiene performance. This study tested the tolerability and acceptability of a new ABHR (EVO9; Ecolab) in healthcare workers under daily working conditions and evaluated the practicability of the corresponding WHO protocol.

Methods: We strictly applied the WHO single product ABHR evaluation protocol. A trained observer assessed hand skin conditions of healthy volunteers using at least $30 \mathrm{ml}$ ABHR per day during their clinical work at baseline, day 3-5 and one month (visit 1-3). Participants rated ABHR tolerability and acceptability at visit 2 and 3. Additionally, we registered study time for participants and study team.

Results: Among 46 volunteers, $76 \%$ were female; $37 \%$ nurses, $28 \%$ physicians. Skin was observer-rated "not" or "incidentally" dry in 64.4\%, 77.8\%, and $90.9 \%$ participants at visit 1, 2, and 3, respectively. EVO9 was scored $\geq 5$ (progressive scale, 1-7) for appearance, intactness, moisture content, and sensation by 95.7\%, 97.7\%, 88.9\%, and 97.8\% participants at visit 3, respectively. All WHO benchmarks were exceeded except for "speed of drying" at visit 2 , and "texture" at visit 2 and 3. Cumulative study time expenditure was 14 days for the observer and four days for participants.

Conclusions: EVO9 was well tolerated and accepted according to the WHO single ABHR evaluation protocol with the potential for improvement for stickiness. The WHO protocol is feasible but requires considerable time and logistics. It does not preclude bias, in this case especially due to the necessary switch to personal dispensers.
\end{abstract}

Keywords: Hand hygiene, Alcohol-based hand rub, Tolerability, Acceptability, World Health Organization

\section{Background}

The World Health Organisation (WHO) 'Guidelines on Hand Hygiene in Healthcare' were issued by WHO Patient Safety in May 2009 on the occasion of the launch of the "Save Lives: Clean Your Hands" initiative [1]. Since publication of the guidelines there has been convincing evidence of an improvement in hand hygiene $(\mathrm{HH})$ practices and that, in turn, has resulted in a reduction of hospital acquired infections and/or transmission of multidrug-resistant organisms [2-6]. The WHO suggests five avenues of action as a multimodal strategy of which system change, i.e. facilitated access to well-tolerated alcohol-based handrub (ABHR), is one component.

\footnotetext{
* Correspondence: aline.wolfensberger@usz.ch

Division of Infectious Diseases and Hospital Epidemiology, University Hospital Zürich, University of Zürich, Raemistrasse 100, Zurich CH-8091, Switzerland
}

However, not all initiatives to improve $\mathrm{HH}$ are successful and, sustaining high levels of $\mathrm{HH}$ compliance among health care personnel are ambitious goals $[7,8]$. Some of the self-reported reasons given for failing to correctly apply hand cleansing include lack of time, inconveniently located and/or scarcity of facilities, forgetfulness, and agents that cause skin irritations and dryness [9]. In fact, skin tolerability has been reported as one of the main reasons for disinclination towards $\mathrm{HH}$ [10-12].

User's acceptance and good skin tolerability are therefore considered being among the most important criteria for the selection of an ABHR [1]. Thus, a product that is pleasant to use with no harmful effect to the hands is a major asset for the promotion of optimal hand hygiene practices.

Ciomed Central

(c) 2015 Wolfensberger et al.; licensee BioMed Central. This is an Open Access article distributed under the terms of the Creative Commons Attribution License (http://creativecommons.org/licenses/by/4.0), which permits unrestricted use, distribution, and reproduction in any medium, provided the original work is properly credited. The Creative Commons Public Domain Dedication waiver (http://creativecommons.org/publicdomain/zero/1.0/) applies to the data made available in this article, unless otherwise stated. 
The WHO provides and promotes the application of two study protocols to evaluate the acceptability and tolerability of an ABHR: "Method 1" for testing a single product planned to be introduced, "Method 2" for comparing two different products [13-15].

The aim of this study was to investigate the tolerability and acceptability of a new ABHR (EVO9; Ecolab) in healthcare workers by using an established WHO protocol, to report the experience with this protocol under real life conditions, and to exemplarily quantify the effort necessary to conduct such a formal evaluation. The study ABHR has successfully been tested according to the European Norm EN1500 and EN12791 and has been registered with Swissmedic under the registration number CHZN3080.

\section{Methods}

\section{Study setting and protocol}

The study was conducted between May and July 2013 at the Division of Infectious Diseases and Infection Control, University Hospital Zurich, Zurich, Switzerland. The methodology was based on the published WHO protocol "Method 1 for Evaluation of tolerability and acceptability of alcohol-based hand rub in use or planned to be introduced" [13]. Three minor modifications were made to the WHO protocol: skin type was assessed with by observer according to Fitzpatrick skin sensitivity type (and not selfassessed by participant), participants were allowed to continue their usual hand care products during the whole study period, and a question on product accessibility was added.

\section{Study population}

The study was carried out in healthy adults of $\geq 18$ years of age. Participants were not allowed to have significant skin or systemic disease or any intolerance to any component of the test preparation. The observer was a medical doctor (AW) trained by an expert who participated in establishing and validating the $\mathrm{WHO}$ protocol (MNC, see acknowledgements).

\section{Study design and endpoints}

Each participant received the test product in a $100 \mathrm{ml}$ personal dispenser. Three visits took place: a baseline visit 1 at day 0 , visit 2 between day 3 and 5 of product use, visit 3 at the study end after one month of product use.

The quantity of product used was measured at visit 2 and 3 to assure a minimal mean daily use of at least $30 \mathrm{ml}$ of the test product.

The primary endpoint was the observer assessment of skin condition of the participants' hands using validated scales with higher scores meaning worse conditions including the items redness (score, 0-4), scaliness (0-3), fissures (0-3), and visual scoring of skin (1-5). This primary endpoint was evaluated at all three study visits [16].

Secondary endpoints were participant assessment of skin tolerability on a rating scale 1-7 including the items appearance, intactness, moisture content, and sensation (all, 'abnormal'-'normal') and overall skin integrity ('very altered'-'perfect') and product acceptability including the items color ('unpleasant'-'pleasant'), smell ('unpleasant'-

\section{Table 1 Participants characteristics}

\begin{tabular}{|c|c|c|}
\hline Question & Answer & Value $(\mathrm{N}=46)$ \\
\hline $\begin{array}{l}\text { Do you have non work- } \\
\text { related activities causing } \\
\text { skin damage?* }\end{array}$ & Yes & $12(26.0 \%)$ \\
\hline \multirow{6}{*}{$\begin{array}{l}\text { Do you normally use of a } \\
\text { skin care hand lotion/ } \\
\text { cream?* }\end{array}$} & As often as possible & $2(4.2 \%)$ \\
\hline & Several times per day & $14(30.4 \%)$ \\
\hline & Once per day & 7 (15.2\%) \\
\hline & $\begin{array}{l}\text { Sometimes depending on } \\
\text { season }\end{array}$ & $15(32.6 \%)$ \\
\hline & Rarely & $5(10.9 \%)$ \\
\hline & Never & $2(4.2 \%)$ \\
\hline \multirow{3}{*}{$\begin{array}{l}\text { Do you develop irritative } \\
\text { dermatitis?** }\end{array}$} & Never & $31(67.4 \%)$ \\
\hline & $\begin{array}{l}\text { Sometimes depending on } \\
\text { season }\end{array}$ & $13(28.3 \%)$ \\
\hline & Always & 0 \\
\hline $\begin{array}{l}\text { Do you develop atopic } \\
\text { dermatitis?** }\end{array}$ & Yes & $2(4.2 \%)$ \\
\hline $\begin{array}{l}\text { Do you develop allergic } \\
\text { rhinitis/allergic } \\
\text { conjunctivitis?** }\end{array}$ & Yes & $15(32.6 \%)$ \\
\hline Are you asthmatic?* & Yes & $2(4.2 \%)$ \\
\hline $\begin{array}{l}\text { Do you have Intolerance } \\
\text { to alcohol?* }\end{array}$ & Yes & 0 \\
\hline \multirow[t]{2}{*}{ Do you work part time?* } & Yes & $19(41.3 \%)$ \\
\hline & $\begin{array}{l}\text { Full time equivalent } \\
\leq 50 \%\end{array}$ & $4(8.7 \%)$ \\
\hline \multirow{4}{*}{$\begin{array}{l}\text { For how long have you } \\
\text { been using alcohol-based } \\
\text { products at work?* }\end{array}$} & First time & $4(8.7 \%)$ \\
\hline & $<1$ year & $2(4.2 \%)$ \\
\hline & $>1$ and $<5$ years & $6(13.0 \%)$ \\
\hline & $>5$ years & $33(71.7 \%)$ \\
\hline \multirow{2}{*}{$\begin{array}{l}\text { Do you think you can } \\
\text { improve your own hand } \\
\text { hygiene compliance?* }\end{array}$} & Yes & $26(56.5 \%)$ \\
\hline & Perhaps & $10(21.7 \%)$ \\
\hline \multirow{2}{*}{$\begin{array}{l}\text { It may be difficult to use } \\
\text { an alcohol based hand } \\
\text { rub because of... }\end{array}$} & Forgetfulness & $\begin{array}{l}\text { Mean, 5.1; } \\
\text { median, } 6\end{array}$ \\
\hline & Lack of time & $\begin{array}{l}\text { Mean, } 5.5 ; \\
\text { median, } 6\end{array}$ \\
\hline \multirow[t]{2}{*}{$\begin{array}{l}\text { (Likert scale 1-7; } 1 \text {, } \\
\text { always; } 7 \text {, never)* }\end{array}$} & Damaged skin & $\begin{array}{l}\text { Mean, } 5.4 ; \\
\text { median, } 6\end{array}$ \\
\hline & $\begin{array}{l}\text { Poor product } \\
\text { accessibility*** }\end{array}$ & $\begin{array}{l}\text { Mean, 5.9; } \\
\text { median, } 6\end{array}$ \\
\hline
\end{tabular}

*One missing answer.

**Two missing answers.

***Question added by the authors outside of the WHO protocol. 
Table 2 Hand hygiene behavior and preference of product

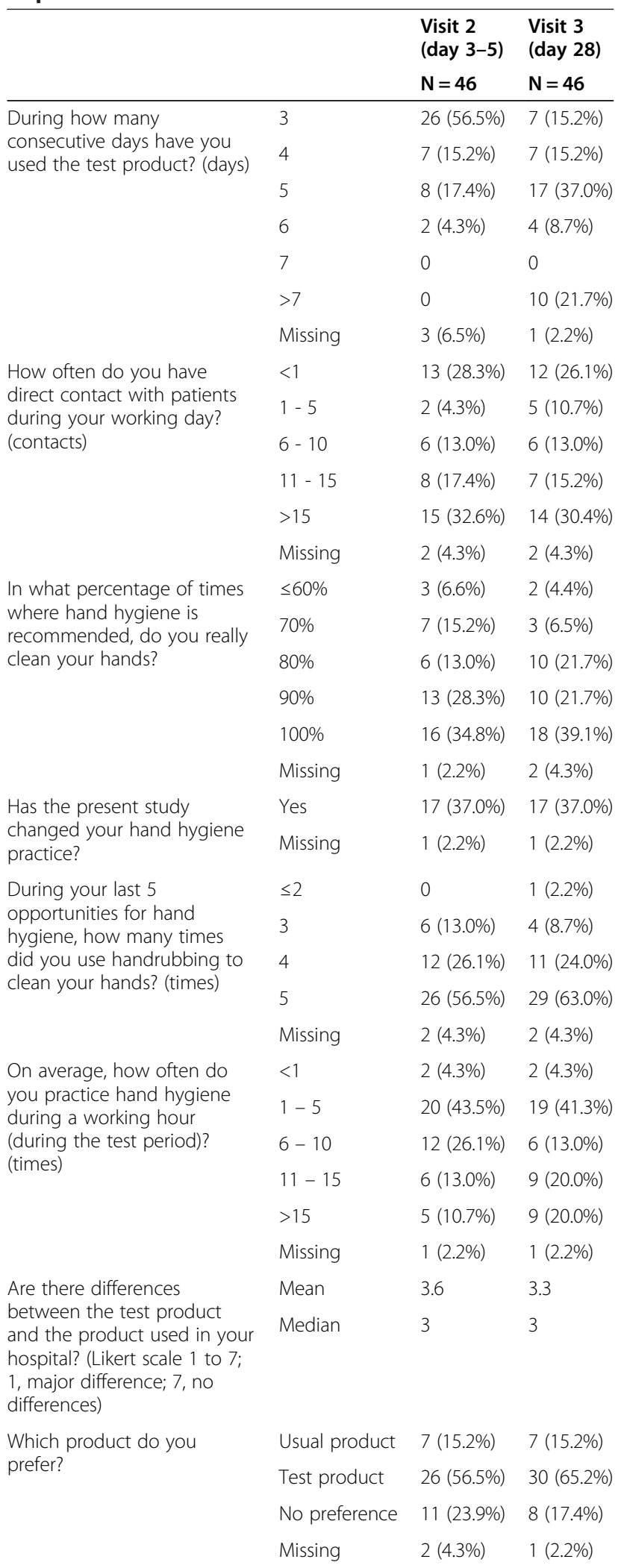

Table 2 Hand hygiene behavior and preference of product (Continued)

\begin{tabular}{llll}
\hline $\begin{array}{l}\text { Do you think that the test } \\
\text { product could improve your } \\
\text { hand hygiene compliance? }\end{array}$ & Mean & 3.6 & 3.4 \\
$\begin{array}{l}\text { (Likert scale } 1 \text { to } 7 ; \text { 1, yes } \\
\text { absolutely; } 7, \text { not at all) }\end{array}$ & 4 & 3 \\
\hline
\end{tabular}

'pleasant'), texture ('very sticky'-'not sticky at all'), irritation ('very irritating'-'not irritating'), drying effect ('very much''not at all'), ease of use ('very difficult'-'very easy'), speed of drying ('very slow'-'very fast'), application ('unpleasant''pleasant'), overall evaluation ('dissatisfied'-'very satisfied'). Participant evaluations were carried out at visit 2 and visit 3.

\section{WHO hand rub quality benchmarks}

WHO defined benchmark criteria for an acceptable quality for $\mathrm{ABHR}$ to help purchasing decision-making. Objective scores for skin condition must score lower than 2 in $\geq 75 \%$ of assessments. Participant evaluation of skin condition must score above 4 in $\geq 75 \%$ of cases. Participant acceptance must score for color and smell above 4 in $\geq 50 \%$ of the answers and above 4 in $\geq 75 \%$ of ratings for the other items in this dimension [13].

\section{Statistical analysis}

The results were interpreted descriptively according to the WHO 'Method 1' [13].

\section{Evaluation of WHO protocol feasibility and applicability}

To evaluate the practicability of the WHO protocol, observer and participant time was registered.

The study was formally accepted by the Ethics board of the Canton of Zurich (ID number KEK-ZH-Nr. 20120444).

\section{Results}

\section{Participants}

Overall, 46 participants out of a staff of approximately 90 were included after having given their informed consent. Participant mean age was 35 years (standard deviation, \pm 12$)$; 35 (76\%) were female; 17 (37\%) were nurses, $13(28 \%)$ medical doctors, five (11\%) students, and 11 (24\%) belonged to other professions. Fitzpatrick skin sun sensitivity types [17] were: type II, 28 (62\%); type III, 14 (31\%); and type I, IV, V, one participant (2\%) each. Eight participants $(17 \%)$ were smokers. The remaining participant characteristics are shown in Table 1, data on hand hygiene behavior and product preference in Table 2 .

\section{Skin tolerability by observer evaluation}

Skin condition met the WHO benchmark at all visits and scores improved over time (Table 3). 
Table 3 Evaluation of skin condition by trained observer

\begin{tabular}{|c|c|c|c|c|}
\hline Item & Skin condition (score) & $\begin{array}{l}\text { Visit } 1 \\
\text { (day 0) } \\
\end{array}$ & $\begin{array}{l}\text { Visit } 2 \\
\text { (day 3-5) }\end{array}$ & $\begin{array}{l}\text { Visit } 3 \\
\text { (day 28) } \\
\end{array}$ \\
\hline \multirow[t]{7}{*}{ Redness } & $\mathrm{N}$ & 46 & 46 & 45 \\
\hline & No redness $(0)$ & $11(24 \%)$ & $16(35 \%)$ & $19(42 \%)$ \\
\hline & Slight redness or blotchy (1) & $28(61 \%)$ & $25(54 \%)$ & $22(49 \%)$ \\
\hline & Moderate redness (2) & $7(15 \%)$ & $4(9 \%)$ & $4(9 \%)$ \\
\hline & Strong redness (3) & 0 & 0 & 0 \\
\hline & Fiery red with oedema (4) & 0 & $1(2)$ & 0 \\
\hline & Proportion with score $<2^{*}$ & $84.7 \%$ & $89.1 \%$ & $91.1 \%$ \\
\hline \multirow[t]{6}{*}{ Scaliness } & $\mathrm{N}$ & 46 & 46 & 45 \\
\hline & No scales (0) & $29(63 \%)$ & $28(61 \%)$ & $33(73 \%)$ \\
\hline & Very slight sporadic scales (1) & $13(28 \%)$ & $16(35 \%)$ & $11(24 \%)$ \\
\hline & Moderate scales (2) & $4(9 \%)$ & $2(4 \%)$ & $1(2 \%)$ \\
\hline & Considerable scales (3) & 0 & 0 & 0 \\
\hline & Proportion with score $<2^{*}$ & $91.3 \%$ & $95.6 \%$ & $97.7 \%$ \\
\hline \multirow[t]{6}{*}{ Fissures } & $\mathrm{N}$ & 46 & 46 & 44 \\
\hline & No fissures (0) & $30(65 \%)$ & $34(74 \%)$ & $37(84 \%)$ \\
\hline & Very fine fissures (1) & $14(30 \%)$ & $12(26 \%)$ & $5(11 \%)$ \\
\hline & Broad, sporadic or several fissures (2) & $2(4 \%)$ & 0 & $2(5 \%)$ \\
\hline & Widespread cracks with haemorrhage or exudate (3) & 0 & 0 & 0 \\
\hline & Proportion with score $<2^{*}$ & $95.7 \%$ & $100 \%$ & $95.7 \%$ \\
\hline \multirow[t]{8}{*}{ Global score } & $\mathrm{N}$ & 45 & 46 & 44 \\
\hline & No dry skin or irritations (0) & $4(9 \%)$ & $8(17 \%)$ & $17(39 \%)$ \\
\hline & Incidental dry skin (1) & $25(56 \%)$ & $28(61 \%)$ & $23(52 \%)$ \\
\hline & Dry skin and/or redness (2) & $13(29 \%)$ & $10(22 \%)$ & $3(7 \%)$ \\
\hline & Very dry, whitish rough skin (3) & $2(4 \%)$ & 0 & $1(2 \%)$ \\
\hline & Chappy skin without haemorrhage or exudate (4) & $1(2 \%)$ & 0 & 0 \\
\hline & Widespread fissures with haemorrhage or exudate (5) & 0 & 0 & 0 \\
\hline & Proportion with score $<2^{*}$ & $64.4 \%$ & $77.8 \%$ & $90.9 \%$ \\
\hline
\end{tabular}

${ }^{*}$ WHO benchmark $\geq 75 \%$.

Skin tolerability by participant evaluation

The second WHO criterion for skin tolerability by participant rating was also fulfilled at both visit 2 and 3 (Figure 1).

\section{Product acceptability by participate evaluation}

The WHO criteria for product acceptability for the items color and fragrance was fulfilled at each time point. The WHO criteria for all the other items were met in all but two categories at visit 2 and in all but one category at visit 3 . The investigational product failed to meet the WHO criterion for acceptability by study participants only for texture at visits 2 and 3 and speed of drying at visit 2. Additionally, while still meeting WHO benchmark 'smell after application' received lower scores than the other items (Figure 2).

\section{Adverse events}

One non-serious adverse event (AE) was reported during the study period. The affected participant complained about erythema and pruritus on his/her hands, which was determined to be a local allergic or irritative reaction to the investigational product. The AE was rated as mild, lasted for four hours and disappeared without any treatment. The participant reported similar skin reactions to other products in the past and was withdrawn from the study without further investigation. There were no serious AEs.

\section{Product consumption}

The test ABHR was used at a mean quantity of $35 \mathrm{ml}$ per day at visit 2 and $37 \mathrm{ml}$ per day thereafter. The required frequency of use criterion according to the WHO 


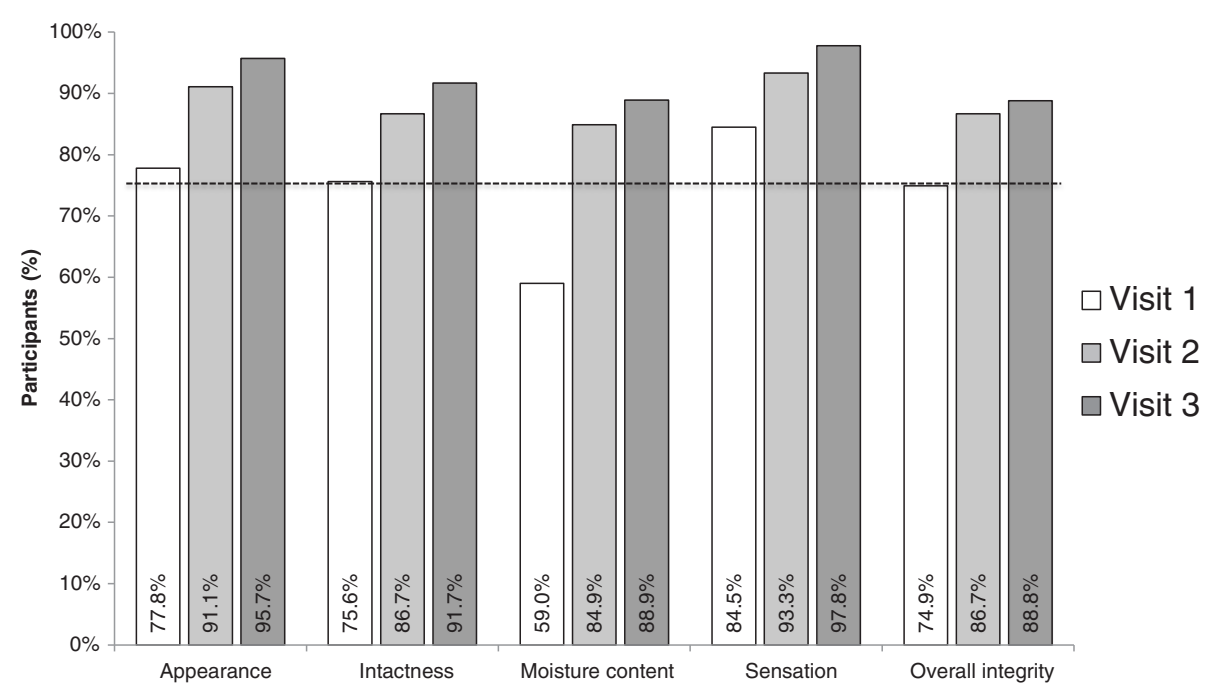

Figure 1 Skin tolerability by participant evaluation. Proportion of participants rating skin tolerability items (Likert scale 1 to 7) $>4$; dashed line, WHO minimal pass criteria for alcohol-based hand rub. Visit 1 took place at baseline, visit 2 at day $3-5$ and visit 3 at one month of test alcohol-based hand rub use.

protocol of a minimum consumption of $30 \mathrm{ml}$ per day was met.

\section{Practicability assessment}

Information, instruction and informed consent procedures required 15 minutes per participant. Time for filling in the questionnaires required five minutes each, time for meeting the observer for evaluation of skin state, distribution and return of bottles accounted for three minutes each. In total every test person spent 40 minutes on study procedures, resulting in 30 hours for all the 46 participants. The observer had to prearrange the study, including preparation of the bottles and questionnaires, which took two working days. Time expenditure for information and recruitment of participants was about two working days. The objective skin evaluation, distribution and return of questionnaires and bottles and measurement of product consumption took

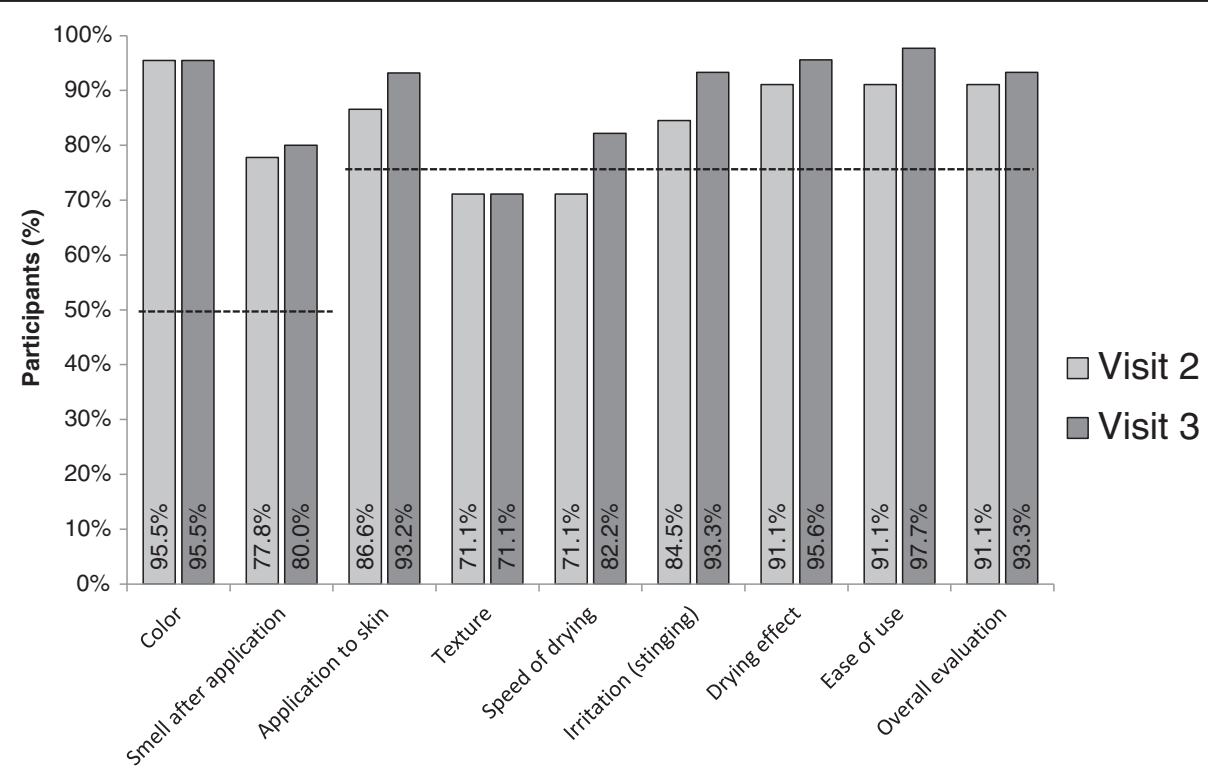

Figure 2 Product acceptability by participant evaluation. Proportion of participants rating skin tolerability items (Likert scale 1 to 7 ) $>4$; dashed line, WHO minimal pass criteria for alcohol-based hand rub. Visit 2 took place at day 3-5 and visit 3 at one month of test alcohol-based hand rub use. 
about 60 minutes per participant, summing up to six working days in this case. Data analysis and calculation took another four working days. In total the observer/ investigator spent 14 working days for conducting the evaluation.

\section{Discussion}

The aim of this study was to investigate the skin tolerability and product acceptability of a new ABHR (EVO9; Ecolab) in healthcare workers under daily working conditions and to evaluate the practicability of the WHO protocol "Method 1 for evaluation of tolerability and acceptability of alcohol-based hand rub in use or planned to be introduced" (WHO 2009). To our knowledge this is the first formal report on the application of the abovementioned WHO protocol.

The primary endpoint concerned participant skin condition rated by a trained observer according to wellestablished dermatological criteria. The test product surpassed the corresponding WHO benchmark. Moreover, there was a trend to improved ratings with time of use in follow-up visits. These findings were corroborated by participants reporting above-benchmark ratings for "skin tolerability by participant" in every category, i.e., appearance, intactness, moisture content, and sensation, at both study visits. In terms of acceptability the test product failed the WHO benchmark only for texture at visit 2 and 3 and speed of drying at visit 2 . After one month of use, $67 \%$ of participants preferred the investigational product over the product they normally used.

However, the results have to be interpreted with some caution. Study procedures made it necessary to provide participants with personal bottles of ABHR, which presented a novelty against the habitual bed- and wallmounted dispensers in our hospital. Many participants told the study observer that they liked the personal ABHR bottles. Such preference might have led to a positive halo effect on product judgment. If feasible, change of provision form for the test product should be avoided since it can lead to positive or negative confounding. For the sake of a real world assessment we allowed participants to continue their habitual hand cream use during the study. This might have offset overall skin condition results favorably but did most likely not change trends over time. Additionally, the quantification in Table 1 that is in accordance with the WHO protocol, allows for comparison with results of other studies. Lastly, it is well known that in an non-blinded study the results tend to be biased towards a beneficial effect of the product under study [18]. This flaw would be mitigated when using the WHO "Method 2" to compare two different products using a randomized blinded protocol.

The WHO protocol proofed to be clear and easy to understand. Yet, its implementation presented some challenges. First, the necessary 14 working days for the observer and four cumulative working days for participants might be perceived as an unusually high workload given the considerable number of potential ABHR available for testing. Thus, if used to select an ABHR for an institution it is advisable to apply this protocol to a limited number of serious ABHR candidates. Second, participants had to use the product for four weeks without interruption for more than five days, otherwise the study duration had to be extended for the same number of days. Fulfilling these requirements in part-time HCWs on irregular shifts proved to be challenging. Third, to prevent inter-individual variation, all skin assessments had to be carried out by the same investigator requiring the person to be available for the whole assessment period.

\section{Conclusion}

The new ABHR (EVO9; Ecolab) was well tolerated and user-accepted with a potential for improvement regarding texture, i.e. stickiness. While the subjective usability and tolerability rating by the users should be interpreted with caution, the skin tolerability assessed by a trained observer may be more reliable. The WHO protocol proofed to be useful but demanding for everyday application.

\section{Competing interests}

Financial support for this study was provided by Ecolab. The funding source was not involved in study design, collection and interpretation of the data, and manuscript submission. The authors declare that they have no competing interests.

\section{Authors' contributions}

AW, ND, JM, EA participated in the planning and execution of the study. AW and HS performed the data analysis and wrote the manuscript. The manuscript was revised and approved by all authors.

\section{Acknowledgements}

The author would like to express their thankfulness to their colleagues who volunteered to participate in this study. Special thanks go to Marie-Noëlle

Chraiti, Geneva, who provided training for the observer.

Received: 23 December 2014 Accepted: 16 March 2015

Published online: 06 May 2015

\section{References}

1. Pittet D, Allegranzi B, Boyce J, World Health Organization World Alliance for Patient Safety First Global Patient Safety Challenge Core Group of E. The World Health Organization Guidelines on Hand Hygiene in Health Care and their consensus recommendations. Infect Control Hosp Epidemiol. 2009;30:611-22.

2. Chen YC, Sheng WH, Wang JT, Chang SC, Lin HC, Tien KL et al. Effectiveness and limitations of hand hygiene promotion on decreasing healthcareassociated 297 infections. PLoS One. 2011;6:e27163

3. Grayson ML, Russo PL, Cruickshank M, Bear JL, Gee CA, Hughes CF, et al. Outcomes from the first 2 years of the Australian National Hand Hygiene Initiative. Med J Aust. 2011;195:615-9.

4. Behnke M, Gastmeier P, Geffers C, Monch N, Reichardt C. Establishment of a national surveillance system for alcohol-based hand rub consumption and change in consumption over 4 years. Infect Control Hosp Epidemiol. 2012;33:618-20.

5. Roberts SA, Sieczkowski C, Campbell T, Balla G, Keenan A. Implementing and sustaining a hand hygiene culture change programme at Auckland District Health Board. N Z Med J. 2012;125:75-85. 
6. Stone SP, Fuller C, Savage J, Cookson B, Hayward A, Cooper B, et al. Evaluation of the national Cleanyourhands campaign to reduce Staphylococcus aureus bacteraemia and Clostridium difficile infection in hospitals in England and Wales by improved hand hygiene: four year, prospective, ecological, interrupted time series study. BMJ. 2012;344:e3005.

7. Borges LF, Rocha LA, Nunes MJ, Gontijo Filho PP. Low compliance to handwashing program and high nosocomial infection in a brazilian hospital. Interdiscip Perspect Infect Dis. 2012;2012:579681.

8. Boyce JM. Update on hand hygiene. Am J Infect Control. 2013;41:S94-96.

9. The World Health Organisation (2009) WHO Guidelines on Hand Hygiene in Health Care: a Summary. [http://whqlibdoc.who.int/hq/2009/WHO_IER_PSP_ 2009.07_eng.pdf?ua=1]

10. Larson E, Killien M. Factors influencing handwashing behavior of patient care personnel. Am J Infect Control. 1982;10:93-9.

11. Larson E, Girard R, Pessoa-Silva CL, Boyce J, Donaldson L, Pittet D. Skin reactions related to hand hygiene and selection of hand hygiene products. Am J Infect Control. 2006;34:627-35.

12. Zimakoff J, Kjelsberg AB, Larsen $\mathrm{SO}$, Holstein B. A multicenter questionnaire investigation of attitudes toward hand hygiene, assessed by the staff in fifteen hospitals in Denmark and Norway. Am J Infect Control. 1992;20:58-64.

13. The World Health Organisation (2009). Tools for evaluation and feedback [http://www.who.int/gpsc/5may/tools/evaluation_feedback/en/]: Protocol for Evaluation of tolerability and acceptability of alcohol-based handrub in use or planned to be introduced: Method 1. [http://www.who.int/entity/ gpsc/5may/Protocol_for_Evaluation_of_Handrub_Meth1.doc?ua=1]

14. The World Health Organisation (2009). Tools for evaluation and feedback [http://www.who.int/gpsc/5may/tools/evaluation_feedback/en/]: Protocol for Evaluation of tolerability and acceptability of alcohol-based handrub in use or planned to be introduced: Method 2. [http://www.who.int/entity/ gpsc/5may/Protocol_for_Evaluation_of_Handrub_Meth2.doc?ua=1]

15. Pittet D, Allegranzi B, Sax H, Chraiti MN, Griffiths W, et al. Double-blind, randomized, crossover trial of 3 hand rub formulations: fast-track evaluation of tolerability and acceptability. Infect Control Hosp Epidemiol. 2007;28:1344-51.

16. Highley DR, Savoyka B, Oneill JJ, Ward JB. A Stereomicroscopic Method For The Determination Of Moisturizing Efficacy In Humans. St. Louis, Mo: Presented May 30, 1976, SCC Annual Seminar; 1975.

17. Fitzpatrick TB. The validity and practicality of sun-reactive skin types I through VI. Arch Dermatol. 1988;124:869-71.

18. Wood L, Egger M, Gluud LL, Schulz KF, Juni P, Altman DG, et al. Empirical evidence of bias in treatment effect estimates in controlled trials with different interventions and outcomes: meta-epidemiological study. BMJ. 2008:336:601-5.

\section{Submit your next manuscript to BioMed Central and take full advantage of:}

- Convenient online submission

- Thorough peer review

- No space constraints or color figure charges

- Immediate publication on acceptance

- Inclusion in PubMed, CAS, Scopus and Google Scholar

- Research which is freely available for redistribution 